\title{
The Use of FTIR and Micro-FTIR Spectroscopy: An Example of Application to Cultural Heritage
}

\author{
Mauro Francesco La Russa, ${ }^{1}$ Silvestro Antonio Ruffolo, ${ }^{1}$ Germana Barone, ${ }^{2}$ \\ Gino Mirocle Crisci, ${ }^{1}$ Paolo Mazzoleni, ${ }^{2}$ and Antonino Pezzino ${ }^{2}$ \\ ${ }^{1}$ Dipartimento di Scienze della Terra, Università della Calabria, Via Pietro Bucci Cubo 12b, Arcavacata di Rende, \\ Cosenza 87036, Italy \\ ${ }^{2}$ Dipartimento di Scienze Geologiche, Università degli studi di Catania, Corso Italia 55, 95129 Catania, Italy
}

Correspondence should be addressed to Mauro Francesco La Russa, mlarussa@unical.it

Received 12 March 2009; Accepted 18 April 2009

Recommended by Maher S. Amer

Micro-FTIR and FTIR spectroscopy is useful for the study of degradation forms of cultural heritage. In particular it permits to identify the degradation phases and to establish the structural relationship between them and the substratum. In this paper, we report the results obtained on marble from a Roman sarcophagus, located in the medieval cloister of St. Cosimato Convent (Rome), and on oolitic limestone from the facade of St. Giuseppe Church in Syracuse (Sicily). The main components found in the samples of both monuments are: gypsum, calcium oxalate, and organic matter due to probably conservation treatments. In particular, the qualitative distribution maps of degradation products, obtained by means of micro-FTIR operating in ATR mode, revealed that the degradation process is present deep inside the stones also if it is not visible macroscopically. This process represents the main cause of crumbling of the substrate. The results of this research highlight the benefits of the $\mu$-FTIR analysis providing useful insights on the polishing and consolidation processes of stone materials.

Copyright () 2009 Mauro Francesco La Russa et al. This is an open access article distributed under the Creative Commons Attribution License, which permits unrestricted use, distribution, and reproduction in any medium, provided the original work is properly cited.

\section{Introduction}

The diagnostic analysis of the degradation process of the monument stone has acquired ever more importance regarding its restoration and maintenance. Such studies require analysis of the materials used and an accurate characterization of the degradation products with the aim of evaluating the effects of the degradation.

Fourier transform-infrared spectroscopy (FTIR) represents a powerful technique in diagnostic analysis of cultural heritage [1-3], in particular the micro-FTIR $(\mu$ FTIR) is more recent technique that improved the potential of vibrational spectroscopy in the field of diagnostic and conservation of art works [4-8].

The reliability of the measurements even with an extremely small amount of sampled material is very high, the high analytical sensitivity and high spatial resolution of $\mu$-FTIR technique allow the identification of micrometric mixtures of compounds that constitute samples and the determination of minor and trace compounds, such as reaction and weathering compounds.

The present paper is a research aimed at characterizing degradation products and determination of the previous restoration works on a roman sarcophagus and on the facade of the Church of San Giuseppe. In particular the roman sarcophagus is located in the cloister of San Cosimato convent in Rome, actually the Regina Margherita Hospital (Rome), while the Church of San Giuseppe is located in the Island of Ortigia, historical centre of the city of Syracusa (Sicily).

\section{The Samples}

The analyzed samples are fragments coming from a Roman sarcophagus, located in the medieval cloister of St. Cosimato Convent (Rome), and from the facade of St. Giuseppe 


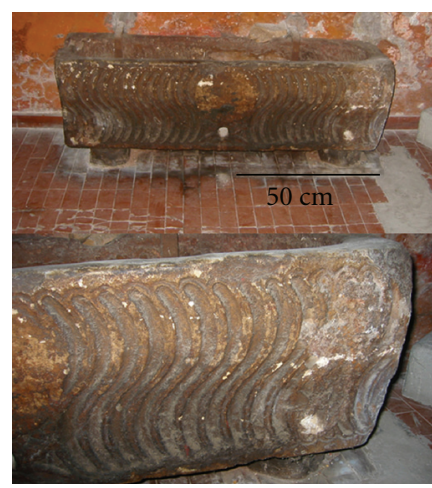

(a)

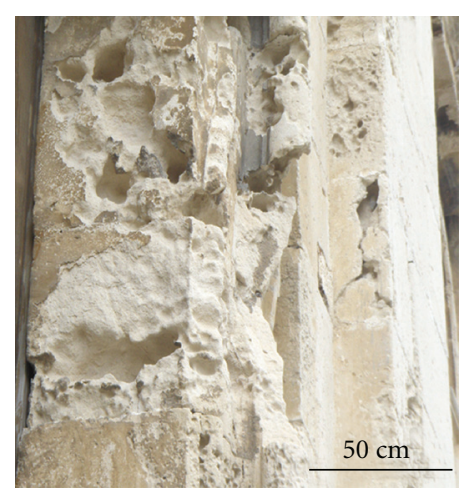

(b)

Figure 1: (a) The Roman sarcophagus; (b) particular of the facade of St. Giuseppe Church.

TABLE 1: List of specimens, sampling point and typology of degradation products.

\begin{tabular}{ll}
\hline Samples & Sampling points and typology of degradation products \\
\hline Sar 1 & Central clipeo, right side, black crust \\
Sar 2 & Sixth strigile, at right-high side of clipeo black crust \\
Sar 4 & Higher left side, orange patinas \\
Sar 5a & Inside left area, black crust \\
Sar 5b & Inside left area, orange patinas \\
\hline
\end{tabular}

Church in Syracuse (Sicily). Before sampling, the stone surface was brushed in order to remove the incoherent deposits. After that, few milligrams of sample were scratched from the surface in different points. Then the samples were crushed, and homogeneous fine powders were obtained. Furthermore some microfragments containing both degraded phases and substrate were taken in order to make stratigraphic thin sections.

2.1. Roman Sarcophagus. The small-sized Roman sarcophagus was made from a single marble piece with a trapezoidal vertical section and has the following measurements: length $124 \mathrm{~cm}$, width $37 \mathrm{~cm}$, and depth $55 \mathrm{~cm}$. The external side of the sarcophagus is adorned with strigile flutes and by a central clipeo, which before restoration, seemed to have no decorations. The sarcophagus has a hole in the centre which suggests a past use as a wash-basin. Inside the sarcophagus, a low pillow is visible on the right side. The marble appears fine grained and covered by a pink-coloured thick layer (Figure 1(a)); in this layer is evident the small portions of detachment material.

The sampling on the sarcophagus is made up of six samples, taken from the degraded areas (Table 1).

2.2. The Church of San Giuseppe. The Church of San Giuseppe was built in the second half of the eighteenth century and is constituted exclusively by oolitic limestone. The building, surmounted by a belfry, has an octagonal plan
TABle 2: List of specimens, sampling point and typology of degradation products.

\begin{tabular}{ll}
\hline Samples & $\begin{array}{l}\text { Sampling points and typology of degradation } \\
\text { products }\end{array}$ \\
\hline SG1 & $\begin{array}{l}\text { Calcarenite with black crust localized on the base } \\
\text { of column right } \\
\text { Calcarenite with black crust localized on the base } \\
\text { of column left } \\
\text { Ca2 }\end{array}$ \\
SG3 & $\begin{array}{l}\text { portcarenite with black crust localized on the } \\
\text { SG4 }\end{array}$ \\
SG5 & $\begin{array}{l}\text { Brown-orange patinas present on the facade } \\
\text { SG6 }\end{array}$ \\
\hline
\end{tabular}

and a single nave with a semicircular apse. The facades show typical baroque architectonical elements [9].

After a careful macroscopic examination, several types of different stone decay were found. In particular alveolitation and granular disintegration are mainly located on the columns of the main portal, while black crusts and brownorange-coloured chromatic alterations are present on almost all of the facade (Figure 1(b)).

The sampling on the facade is made up of six samples, taken from the degraded areas (Table 2).

\section{Experimental}

Fourier transform-infrared spectroscopy (FTIR) was performed for a mineralogical characterization of the powdered samples by means of comparison to a data base [10]. The equipment used was a Nicolet 380 with a Smart Orbit accessory used in the following arrangement: a K-Br beamsplitter, an HP-DTGS-KBr detector, and an Ever-Glow lamp used as source. In this configuration, the resolution was $4 \mathrm{~cm}^{-1}$. The great advantage of this spectroscopic technique is the high sensibility which allows the detection of many components, even at very low amounts. 
The qualitative distribution maps of mineralogical phases, performed on thin sections, have been obtained by using a micro-Fourier transform-infrared spectrometer $(\mu$ FTIR) Spotlight 200 (Perkin Elmer) microscope, equipped with an MCT detector cooled by liquid nitrogen, a germanium $\mu$ ATR crystal, and a computer-controlled mapping stage programmable in the $x$ and $y$ directions. The spectra were recorded at $4 \mathrm{~cm}^{-1}$ resolution, mode with a spot of $100 \times 100 \mu \mathrm{m}^{2}$.

Point-by-point spectral mapping of the thin section was carried out in a grid pattern with the computer-controlled microscope stage with a spot of $100 \mu \mathrm{m} \times 100 \mu \mathrm{m}$. Each spectrum was collected between 4000 and $700 \mathrm{~cm}^{-1}$ at a spectral resolution of $4 \mathrm{~cm}^{-1}$. The map spectra were collected with 4 scans for each spectrum. Maps have a resolution of 625 dots and a spatial resolution of $100 \mu \mathrm{m}$. They are based on the compare correlation value (calculated by Spotlight 200 software) of the recorded spectra with references ones. A compare correlation map indicates the areas of a map, where the spectra are most similar to a reference spectrum.

\section{Results and Discussion}

4.1. FTIR Analysis. The spectroscopic study was aimed at essentially characterizing the main degradation products present on both typologies of materials sampled.

In all the analysed samples, the stretching vibrations of calcium carbonate $\left(\mathrm{CaCO}_{3}\right)$ peaked at 1409,705 , and $611 \mathrm{~cm}^{-1}$ and identified since the substrate (marble and oolitic limestone).

The IR spectra of all samples (taken from sarcophagus and facade of S. Giuseppe Church) showed the presence of typical vibration bands of calcium sulphate hydrate, commonly called gypsum $\left(\mathrm{CaSO}_{4} \times 2 \mathrm{H}_{2} \mathrm{O}\right)$, centred at 1109,669 , and $596 \mathrm{~cm}^{-1}$ as well as the stretching and deformation vibrations of the $\mathrm{O}-\mathrm{H}$ bond of water at 3525 , $3492,3401 \mathrm{~cm}^{-1}$ and at 1692 and $1627 \mathrm{~cm}^{-1}$, respectively. In all the analyzed samples, representative band of silicates was present at 1032 and $1006 \mathrm{~cm}^{-1}$. Gypsum originates from the transformation of calcite in the presence of sulphur oxides, while silicate was subsequently embedded in the crust due to the deposition of wind-born particles [11] (Figure 2).

Most notably, the prominent bands of calcium oxalate $\left(\mathrm{CaC}_{2} \mathrm{O}_{4} n \mathrm{H}_{2} \mathrm{O}\right)$ at 1324 and $780 \mathrm{~cm}^{-1}$ were present [12]. The band presence at $1324 \mathrm{~cm}^{-1}$ is typical of whewellite represent stretching $\mathrm{C}=\mathrm{O}$ [13]. As gypsum is also present, the calcium oxalate band around $1640-1620 \mathrm{~cm}^{-1}$ cannot be clearly established (Figure 2) [14].

The presence of organic matter was highlighted exclusively on the sarcophagus samples by the weak bands at $2950 \mathrm{~cm}^{-1}, 2919 \mathrm{~cm}^{-1}$, and $2855 \mathrm{~cm}^{-1}$ attributed to the stretching of $\mathrm{CH}_{3}$ and $\mathrm{CH}_{2}$ groups (Figure 2). The weak absorbance peak at $729 \mathrm{~cm}^{-1}$ may be assigned to the rocking of $\mathrm{CH}_{2}$ group $\left(-\left(\mathrm{CH}_{2}\right)_{n}\right.$ with $\left.\mathrm{n} \geq 4\right)$. Furthermore, there is no evidence of the presence of carbonyl groups (in the range of $1700-1750 \mathrm{~cm}^{-1}$ ), so it can be presumed that an aliphatic hydrocarbon compound, such as paraffin [15], was used as a protective treatment.

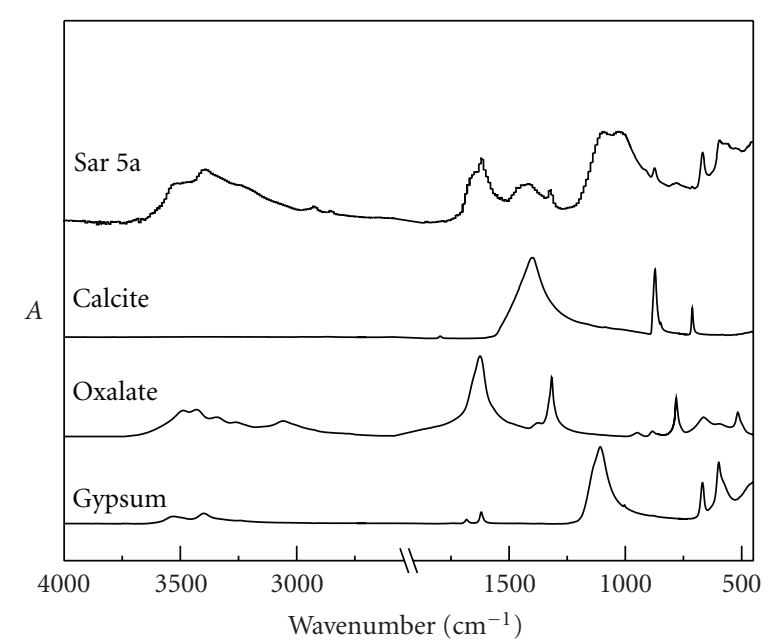

FIGURE 2: FTIR spectra of samples SG5, Sar 5a reference spectra (taken from ATR-FTIR library) of wax, calcite, oxalate, and gypsum are also reported.

From these results, it can be presumed that an organic compound should not be used for protection treatment. In fact, the areas where the organic compounds were found showed a chromatic alteration that could be related to the degradation process of the organic matter used in the previous restorations.

4.2. $\mu$-FTIR Analysis. Ultrathin sections of samples containing patinas were studied by using a $\mu$-FTIR microscope. The analysis was aimed at investigating the superficial layer coating of the stone substrate.

The qualitative distribution maps of calcite, gypsum, and whewellite have been obtained by using the correlation of the recorded spectra with the reference ones of calcite, gypsum, and whewellite. The bright areas indicate regions of high correlation (therefore high concentration), while dark areas indicate a low concentration (Figure 3 ).

In Figure 3(c) it is evident that gypsum is present in different areas of the bulk. In all samples investigated we have found a penetration of the gypsum into the substrate. Unfortunately, from the samples taken from the artwork, it is very hard to give a value to the penetration depth because we found gypsum dishomogeneously distributed throughout the bulk, so deeper samples are needed to assess the penetration degree.

This process represents the main cause of crumbling of the substrate. As described in literature [16], whewellite is more localized within the sample (Figure 3(d)) and often combined with black crust.

The maps of sample of S. Giuseppe Church are also based on the correlation of the recorded spectra with the reference ones of gypsum and whewellite.

The bright areas indicate regions of high correlation (therefore high concentration), while dark areas indicate a low concentration (Figure 4). 


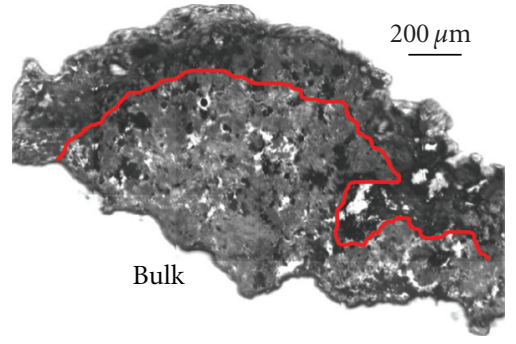

(a)

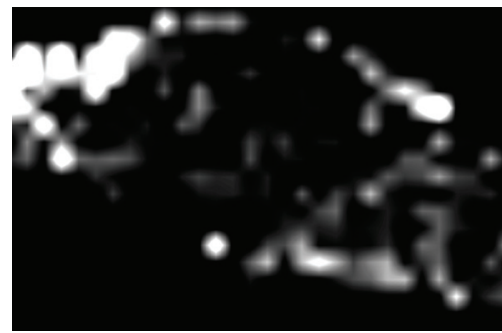

(c)

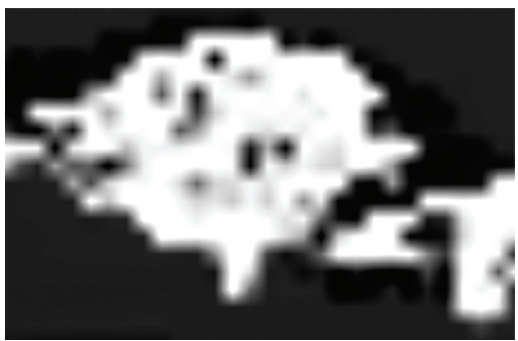

(b)

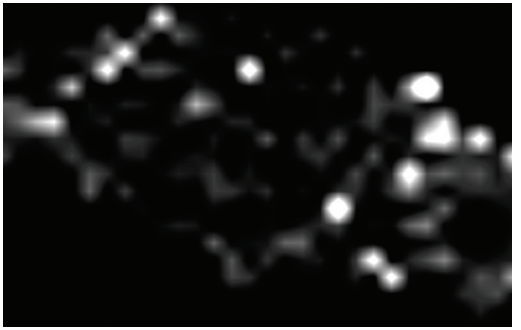

(d)

FIGURE 3: (a) Ultrathin section analyzed, (b) distribution maps of calcite, (c) gypsum, and (d) whewellite obtained by $\mu$-FTIR-ATR spectroscopy. The bright areas indicate regions of high concentration, while dark areas indicate a low concentration.

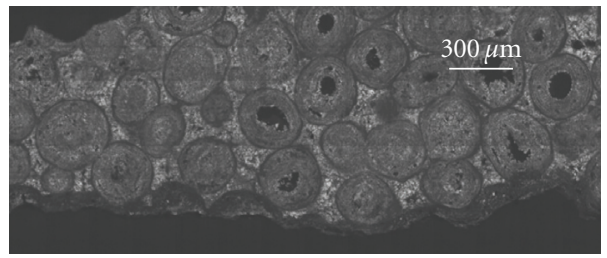

(a)

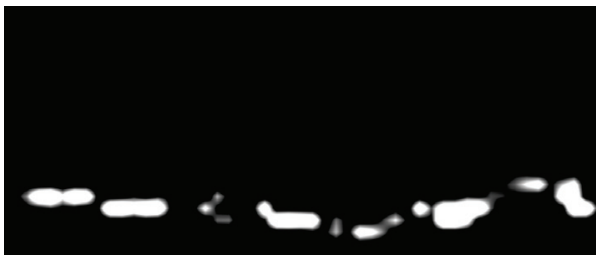

(c)

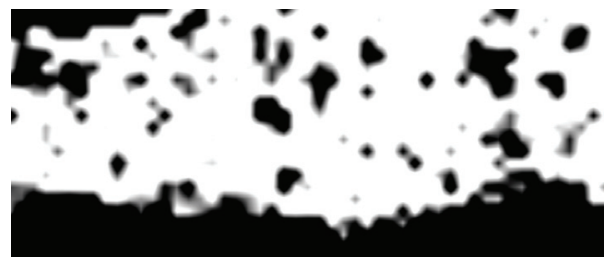

(b)

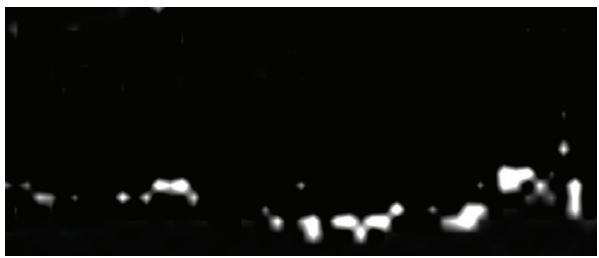

(d)

FIgure 4: (a) Thin section analyzed (b) distribution maps of calcite, (c) gypsum, and (d) calcium oxalate obtained by $\mu$-FTIR-ATR. The bright areas indicate regions of high concentration, while dark areas indicate a low concentration.

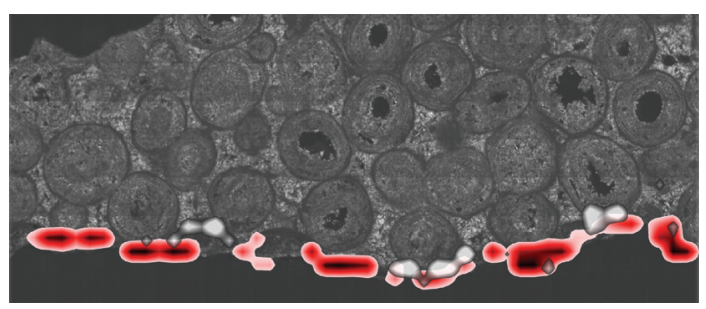

FIGURE 5: Thin section analyzed. Distribution map gypsum (light to dark red) and calcium oxalate (grey to white) obtained by $\mu$-FTIRATR.

They confirm the presence of gypsum and whewellite, as shown in the FTIR analysis, and also confirmed that degradation products are exclusively sited on the external surface of the sample. Figure 5 is obtained by overlap gypsum and oxalate maps, it is evident that the distribution of the two mineralogical phases, in particular oxalate, is mainly located below the gypsum.

This analytical technique has provided useful information for the manufact cleaning process. In fact, during restoration, the thin oxalate layer lying below the gypsum crust was preserved.

This patina is considered very useful for the protection [17] of stones, even if it involves only the surface of the sample, because the surface is not alternated. The characteristics of absorbance and wetting do not change; the porosity decreases but does not interfere with the passing of 
liquid water; therefore, resistance towards acid substances is increased.

\section{Conclusions}

This paper represents an example of diagnostic analysis for conservation of historical cultural heritage. Results, obtained by using spectroscopic analytical techniques, allow the awareness on degradation products as well as the conservational state of marble and calcarenite to be advanced. In particular, the combined used of FTIR and $\mu$-FTIR analysis highlighted the presence and the distribution of gypsum and calcium oxalate on the stone surface.

Furthermore, this research confirms the importance of infrared spectroscopy for a semiquantitative determination of both inorganic and organic phases and demonstrates how the micro-FTIR provides information about restoration process.

In particular, by means of degradation products mapping, it is possible to discriminate with cleaning, and consolidation methods are more appropriate for preserving the oxalate layers that represent a natural protective coating.

\section{References}

[1] D. Bersani, E. Campani, A. Casoli, P. P. Lottici, and I.-G. Marino, "Spectroscopic study of the degradation products in the holy water fonts in Santa Maria della Steccata Church in Parma (Italy)," Analytica Chimica Acta, vol. 610, no. 1, pp. 7479, 2008.

[2] M. T. Doménech Carbó, F. Bosch Reig, J. V. Gimeno Adelantado, and V. Periz Martínez, "Fourier transform infrared spectroscopy and the analytical study of works of art for purposes of diagnosis and conservation," Analytica Chimica Acta, vol. 330, no. 2-3, pp. 207-215, 1996.

[3] N. Salvadó, S. Butí, M. J. Tobin, E. Pantos, A. J. N. W. Prag, and T. Pradell, "Advantages of the use of SR-FT-IR microspectroscopy: applications to cultural heritage," Analytical Chemistry, vol. 77, no. 11, pp. 3444-3451, 2005.

[4] S. Bruni, F. Cariati, F. Casadio, and L. Toniolo, "Identification of pigments on a XV century illuminated parchment by Raman and FTIR microspectroscopies," Spectrochimica Acta Part A, vol. 55, no. 7-8, pp. 1371-1377, 1999.

[5] M. Spring, C. Ricci, D. A. Peggie, and S. G. Kazarian, "ATRFTIR imaging for the analysis of organic materials in paint cross sections: case studies on paint samples from the National Gallery, London," Analytical and Bioanalytical Chemistry, vol. 392 , no. $1-2$, pp. 37-45, 2008.

[6] R. Mazzeo, S. Prati, M. Quaranta, E. Joseph, E. Kendix, and M. Galeotti, "Attenuated total reflection micro FTIR characterization of pigment-binder interaction in reconstructed paint films," Analytical and Bioanalytical Chemistry, vol. 392, no. 12, pp. 65-76, 2008.

[7] A. Nevin, J. L. Melia, I. Osticioli, G. Gautier, and M. P. Colombini, "The identification of copper oxalates in a 16th century Cypriot exterior wall painting using micro FTIR, micro Raman spectroscopy and Gas Chromatography-Mass Spectrometry," Journal of Cultural Heritage, vol. 9, no. 2, pp. 154-161, 2008.

[8] D. Ajò, U. Casellato, E. Fiorin, and P. A. Vigato, "Ciro Ferri's frescoes: a study of painting materials and technique by SEM-EDS microscopy, X-ray diffraction, micro FT-IR and photoluminescence spectroscopy," Journal of Cultural Heritage, vol. 5, no. 4, pp. 333-348, 2004.

[9] L. Acerra, Architettura religiosa in Ortigia, Arnaldo Lombardi Editore, Syracuse, Italy, 1995.

[10] W. P. Griffith, "Advances in Raman and infrared spectroscopy of minerals," in Spectroscopy of Inorganic-Based Materials, R. J. H. Clark and R. E. Hester, Eds., pp. 119-186, John Wiley \& Sons, Chichester, UK, 1987.

[11] P. Maravelaki-Kalaitzaki, "Black crusts and patinas on Pentelic marble from the Parthenon and Erechtheum (Acropolis, Athens): characterization and origin," Analytica Chimica Acta, vol. 532, no. 2, pp. 187-198, 2005.

[12] L. Rampazzi, A. Andreotti, I. Bonaduce, M. P. Colombini, C. Colombo, and L. Toniolo, "Analytical investigation of calcium oxalate films on marble monuments," Talanta, vol. 63, no. 4, pp. 967-977, 2004.

[13] G. Biscontin and S. Volpin, "Indagine sulle patine ad ossalato mediante FTIR," in Le pellicole ad ossalati: origine e significato nella conservazione delle opere d'arte, pp. 151-163, Centro C.N.R. "Gino Bozza" Politecnico di Milano, Milano, Italy, October 1989.

[14] A. Lluveras, S. Boularand, J. Roqué, M. Cotte, P. Giráldez, and M. Vendrell-Saz, "Weathering of gilding decorations investigated by SR: development and distribution of calcium oxalates in the case of Sant Benet de Bages (Barcelona, Spain)," Applied Physics A, vol. 90, no. 1, pp. 23-33, 2008.

[15] M. R. Derrick, D. Stulik, and J. M. Landry, Infrared Spectroscopy in Conservation Science, Scientific Tools for Conservation, Getty Conservation Institute, Los Angeles, Calif, USA, 1999.

[16] L. Appolonia, M. Giamello, and G. Sabatini, "Caratterizzazione stratigrafica delle pellicole ad ossalato di calcio mediante osservazioni in sezione ultrasottile e microdiffratometria," in Proceedings of the 2nd International Symposium on the Oxalate Films in the Conservation of Works of Art, pp. 360-376, EDITEAM, Bologna, Italy, March 1996.

[17] M. Matteini, A. Moles, and S. Giovannoni, "Calcium oxalates as a protective mineral system for wall paintings: methodology and analyses," in Proceedings of 3rd International Symposium on the Conservation of Monuments in the Mediterranean Basin, pp. 155-161, S.B.A.S., Venice, Italy, June 1994. 


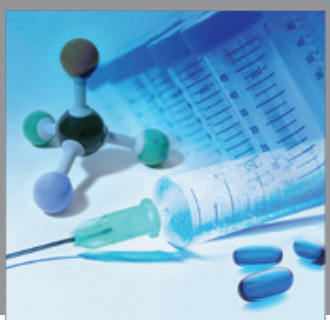

International Journal of

Medicinal Chemistry

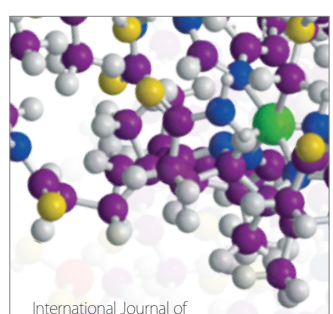

Carbohydrate Chemistry

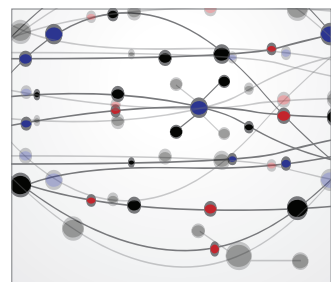

The Scientific World Journal
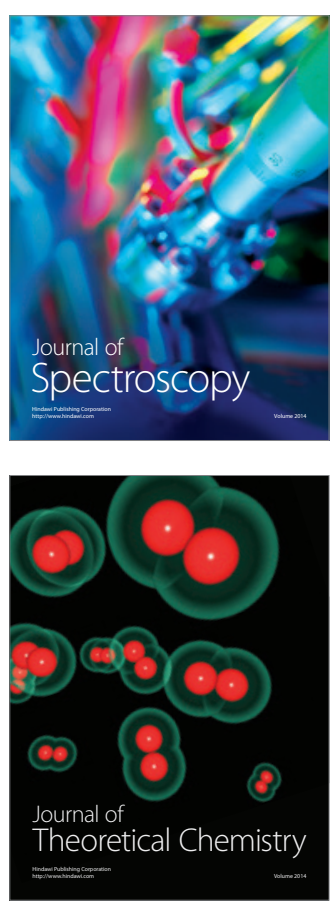
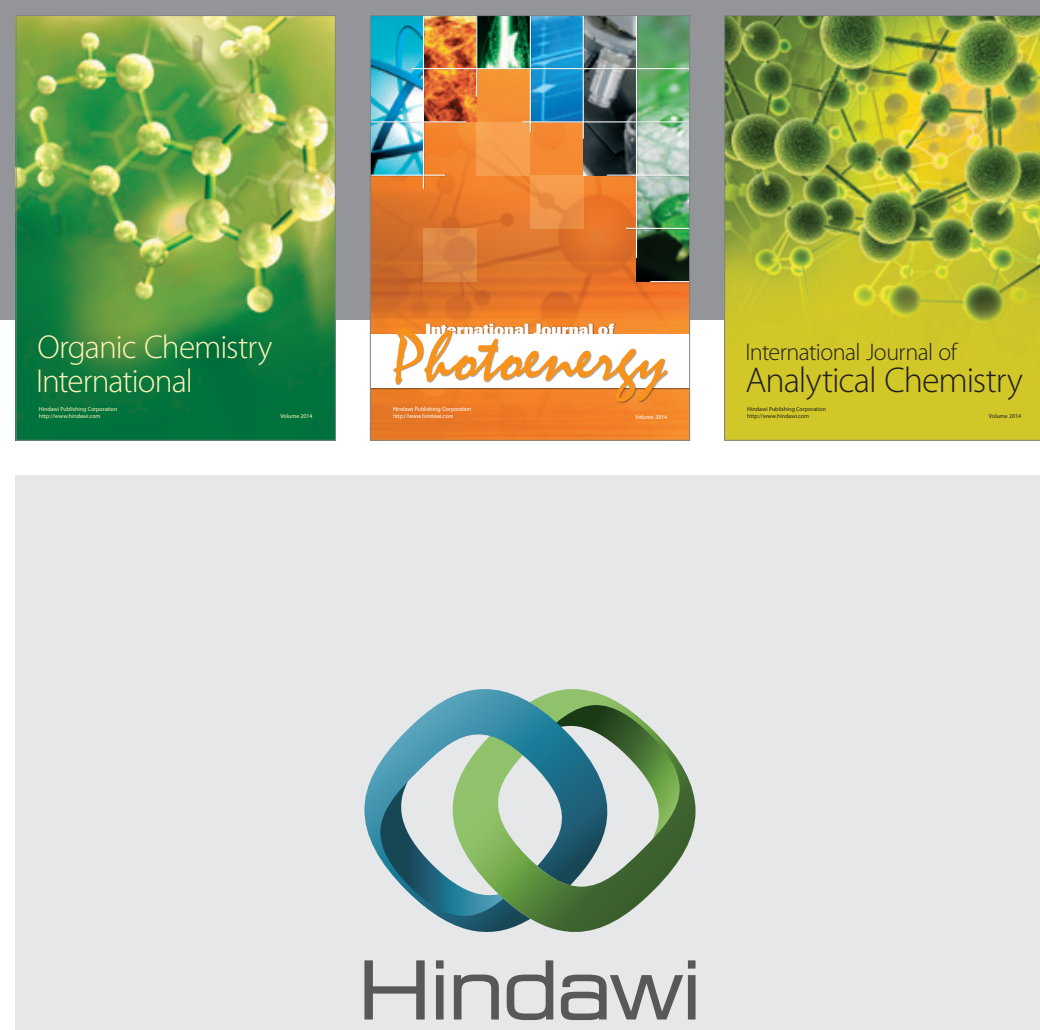

Submit your manuscripts at

http://www.hindawi.com
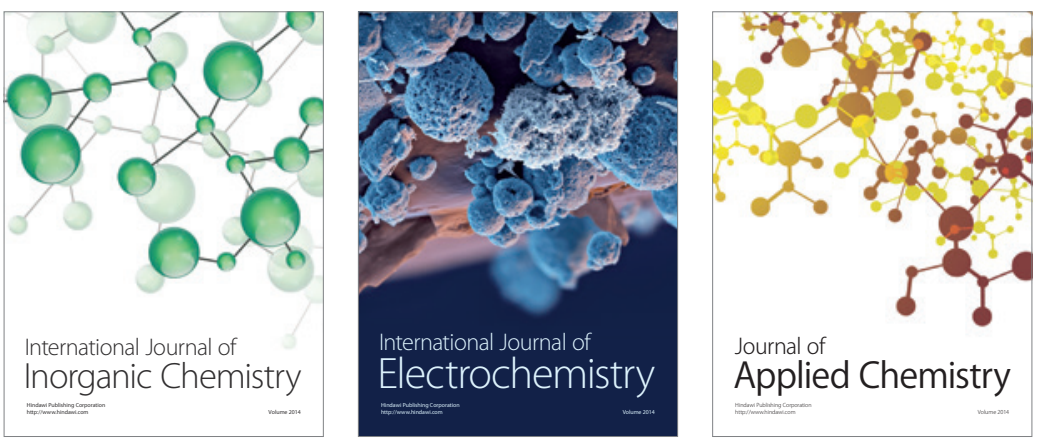

Journal of

Applied Chemistry
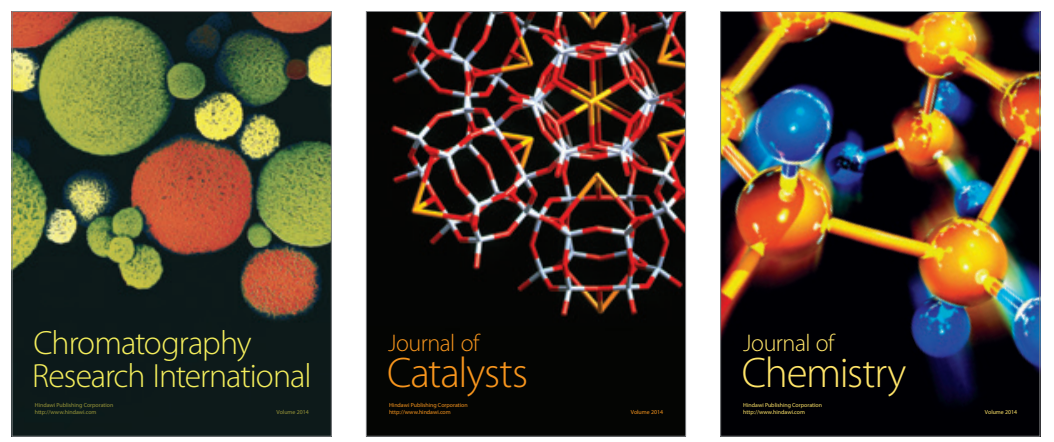
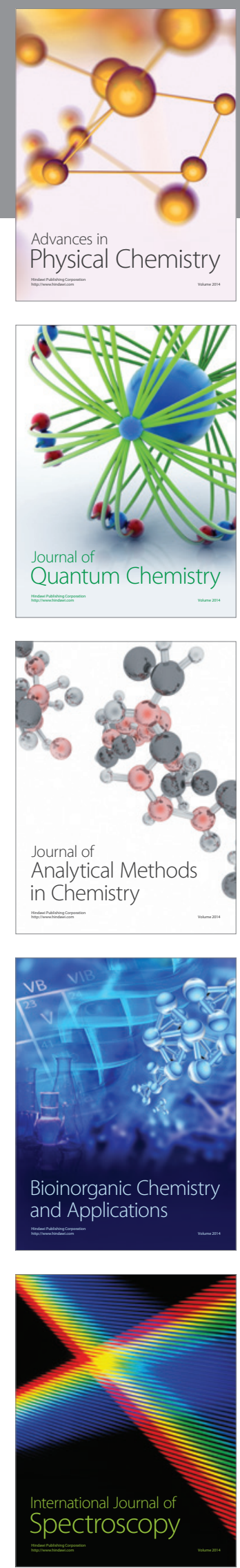